\title{
Respiratory System Findings Reason Not Done
}

National Cancer Institute

\section{Source}

National Cancer Institute. Respiratory System Findings Reason Not Done. NCI

Thesaurus. Code C123994.

The explanation given as to why respiratory system test was not performed. 